LETTER TO THE EDITOR

\title{
Flow cytometry defined cytoplasmic immunoglobulin index is a major prognostic factor for progression of asymptomatic monoclonal gammopathies to multiple myeloma (subset analysis of SWOG S0120)
}

Blood Cancer Journal (2016) 6, e410; doi:10.1038/bcj.2016.19; published online 25 March 2016

Multiple myeloma (MM) is a clonal plasma cell (PC) disorder characterized by end organ damage that is in turn characterized by CRAB criteria (calcium and creatinine elevation, anemia and bone lesions). ${ }^{1}$ It is commonly accepted that nearly all cases of $\mathrm{MM}$ are preceded by a clinically benign phase of monoclonal gammopathy of undetermined significance (MGUS) that evolves through a stage of smoldering multiple myeloma (SMM) without end organ damage, ${ }^{2}$ collectively referred to as asymptomatic monoclonal gammopathies (AMG). ${ }^{3}$ Although traditionally SMM is considered more prone to MM progression than MGUS, additional variables, such as involved-to-uninvolved free light-chain ratio ${ }^{4}$ and magnetic resonance imaging-defined focal lesion number and size, ${ }^{5}$ have been linked to progression to MM and form the basis for the newest International Myeloma Working Group criteria for $\mathrm{MM}^{6}{ }^{6}$ As the treatment of $\mathrm{MM}$ has been greatly advanced, emphasis has been placed on identifying patients with AMG at high risk of progression to MM so that, with earlier treatment, end organ damage can be minimized. ${ }^{7}$ Many new high-risk variables have indeed been identified such as level of circulating plasma cells ${ }^{8}$ and gene expression profiling (GEP). ${ }^{9,10}$

We have previously reported that two-parameter flow cytometry of DNA and cytoplasmic light-chain immunoglobulin (DNA/CIG) is highly predictive of progression-free and overall survival in newly diagnosed MM treated with Total Therapy. ${ }^{11}$ In

Table 1. Cox regression for time to progression to MM

\begin{tabular}{|c|c|c|c|}
\hline \multirow[t]{2}{*}{ Variables } & \multirow[t]{2}{*}{$\mathrm{n} / \mathrm{N}(\%)$} & \multicolumn{2}{|c|}{ Time to treatment for $M M$} \\
\hline & & $H R(95 \% \mathrm{Cl})$ & P-value \\
\hline \multicolumn{4}{|l|}{ Univariate } \\
\hline Age $\geqslant 65$ years & $49 / 110(45 \%)$ & $3.49(1.58,7.69)$ & $<0.001$ \\
\hline Female & $52 / 110(47 \%)$ & $0.67(0.32,1.42)$ & 0.295 \\
\hline White & $91 / 110(83 \%)$ & $7.11(0.97,52.24)$ & 0.024 \\
\hline Albumin $<3.5 \mathrm{~g} / \mathrm{dl}$ & $21 / 110(19 \%)$ & $4.39(2.10,9.15)$ & $<0.001$ \\
\hline $\mathrm{B} 2 \mathrm{M} \geqslant 3.5 \mathrm{mg} / \mathrm{l}$ & $32 / 109$ (29\%) & $2.85(1.37,5.92)$ & 0.003 \\
\hline $\mathrm{B} 2 \mathrm{M}>5.5 \mathrm{mg} / \mathrm{l}$ & $6 / 109$ (6\%) & $1.54(0.37,6.50)$ & 0.552 \\
\hline Creatinine $\geqslant 2 \mathrm{mg} / \mathrm{dl}$ & $1 / 110(1 \%)$ & $0.00(0.00)$ & 0.562 \\
\hline $\mathrm{CRP} \geqslant 8 \mathrm{mg} / \mathrm{l}$ & $28 / 110(25 \%)$ & $0.83(0.34,2.04)$ & 0.685 \\
\hline $\mathrm{Hb}<10 \mathrm{~g} / \mathrm{dl}$ & 4/110 (4\%) & $4.23(1.26,14.14)$ & 0.011 \\
\hline $\mathrm{LDH} \geqslant 190 \mathrm{U} / \mathrm{I}$ & $12 / 110(11 \%)$ & $0.69(0.16,2.91)$ & 0.614 \\
\hline$M$ Protein $\geqslant 3 \mathrm{~g} / \mathrm{dl}$ & $17 / 109(16 \%)$ & $7.52(3.58,15.82)$ & $<0.001$ \\
\hline $\mathrm{BMPC} \geqslant 10 \%$ & $72 / 110(65 \%)$ & $5.43(1.64,17.96)$ & 0.002 \\
\hline Involved light chain $>10 \mathrm{mg} / \mathrm{dl}$ & $32 / 86(37 \%)$ & $1.56(0.73,3.34)$ & 0.248 \\
\hline Involved/uninvolved ratio > 8 & $45 / 86(52 \%)$ & $2.51(1.10,5.75)$ & 0.024 \\
\hline Cytogenetic abnormalities & $18 / 110(16 \%)$ & $3.83(1.77,8.27)$ & $<0.001$ \\
\hline GEP 70-gene risk $>-0.26$ & $28 / 84(33 \%)$ & $6.39(2.59,15.77)$ & $<0.001$ \\
\hline GEP 4-gene score $\geqslant 9.28$ & $10 / 84(12 \%)$ & $7.57(3.14,18.26)$ & $<0.001$ \\
\hline Number of stem lines $\geqslant 2$ & $64 / 110(58 \%)$ & $3.29(1.34,8.10)$ & 0.006 \\
\hline Any aneuploidy & $70 / 110(64 \%)$ & $2.52(1.03,6.19)$ & 0.037 \\
\hline Total LCR\% > 17 & $20 / 110(18 \%)$ & $10.92(5.14,23.16)$ & $<0.001$ \\
\hline Any $\mathrm{Clg}<3.6$ & $26 / 110(24 \%)$ & $7.90(3.75,16.66)$ & $<0.001$ \\
\hline \multicolumn{4}{|l|}{ Multivariate } \\
\hline$M$ Protein $\geqslant 3 \mathrm{~g} / \mathrm{dl}$ & $17 / 109$ (16\%) & $4.57(2.08,10.04)$ & $<0.001$ \\
\hline Total LCR\% > 17 & $20 / 109$ (18\%) & $4.72(2.07,10.76)$ & $<0.001$ \\
\hline Any $\mathrm{Clg}<3.6$ & $26 / 109$ (24\%) & $3.97(1.75,8.99)$ & $<0.001$ \\
\hline
\end{tabular}

Abbreviations: BMPC, bone marrow plasma cells; $\mathrm{Cl}$, confidence interval; Clg, cytoplasmic immunoglobulin index; CRP, C-reactive protein; GEP, gene expression profiling; HR, hazard ratio; LCR, light chain restricted; LDH, lactate dehydrogenase; MM, Multiple myeloma, NS2, not significant at 0.005 level. $P$-value from score $x^{2}$-test in Cox regression. NS2- Multivariate results not statistically significant at 0.05 level. All univariate $P$-values reported regardless of significance. Multivariate model uses stepwise selection with entry level 0.1 and variable remains if it meets the 0.05 level. A multivariate $P$-value $>0.05$ indicates variable forced into model with significant variables chosen using stepwise selection. 
the current subset analysis of S0120, we have investigated whether the DNA/CIG assay can also identify patients with AMG at high risk for progression to MM requiring therapy (time to therapy, TT). ${ }^{12}$ Of 254 patients enrolled at the University of Arkansas in the observational SWOG S0120 protocol with AMG, 110 had evaluable DNA/CIG information and retained AMG status according to the revised International Myeloma Working Group criteria for $\mathrm{MM}^{6}{ }^{6}$ All patients underwent detailed clinical staging as previously reported. ${ }^{9,10}$ DNA/CIG assay was performed on whole bone marrow aspirates along with metaphase cytogenetics and GEP of CD138+ purified PC. ${ }^{13}$ Imaging studies involved metastatic bone surveys and, in the majority of the cases, magnetic resonance imaging examination of the axial and appendicular skeleton.

Details of the DNA/CIG method have been published elsewhere. ${ }^{14,15}$ A technical modification of the assay was applied uniformly since August 2006. The assay is based on the twoparameter flow cytometry of cytoplasmic immunoglobulin and DNA of whole bone marrow aspirates. Single-cell suspensions were exposed to anti-light-chain reagents (Dako Kappa and Lambda light chain $\mathrm{F}(\mathrm{AB})_{2} / \mathrm{FITC}$ conjugated) and then counterstained for DNA with propidium iodide with the addition of RNase. To quantitate the cellular DNA content, DNA index (DI) ${ }^{16}$ was determined and calculated as the ratio of the mean for each lightchain-positive G0/1 DNA peak divided by the mean of the lightchain-negative diploid G0/1 peak on the $X$ axis. A DI between 0.99 and 1.01 was referred to as diploid, while hyperdiploid implied $\mathrm{DI}>1.01$ and hypodiploid $\mathrm{DI}<0.99$. The excess of kappa- or lambda-positive cells identified the involved or light-chainrestricted (LCR) cell population, the percentage of which was calculated in relation to the total number of gated events. Among the LCR cell population, discrete populations of cells with different DI were identified, which we refer to from here on as DNA stem lines. The involved DNA stem line with the highest percentage was considered dominant. To quantitate the cytoplasmic immunoglobulin content of a light-chain-positive population, the cytoplasmic immunoglobulin index $(\mathrm{Clg})$ was used and calculated from the ratio of the geometric mean of the $Y$ axis (cytoplasmic immunoglobulin fluorescence intensity) for the light-chainpositive G0/1 peak divided by the $Y$ axis geometric mean of the light-chain-negative diploid G0/1 population. The $\mathrm{Clg}$ of each distinct DNA stem line was calculated as explained above.

Kaplan-Meier methods were used to generate survival distribution graphs, and comparisons were made employing the log-rank test. For continuous variables, the running log-rank method was applied for the calculation of optimal cutoff points. The $R^{2}$ statistic was used to evaluate the predictive power of different models. Wilcoxon tests were used to compare the medians of continuous measurements between groups.

The characteristics of the 110 patients lacking the revised International Myeloma Working Group criteria for MM are portrayed in Supplementary Table 1. The median follow-up time for the 110 patients was 4.8 years. Aneuploidy by DNA/CIG was evident in $64 \%$, all of whom had hyperdiploid stem lines, while additional hypodiploid abnormalities were present in two cases. Low hemoglobin $(<10 \mathrm{~g} / \mathrm{dl})$ pertained to only $4 \%$ (non-plasma cell dyscrasia-related reasons) while creatinine $\geqslant 2 \mathrm{mg} / \mathrm{dl}$ was evident in one case due to hypertension-related nephrosclerosis. Metaphase cytogenetic abnormalities (CA) were documented in $16 \%$, a GEP70 score $\geqslant-0.26^{\text {(ref. } 3)}$ pertained to $33 \%$ and a recently defined novel GEP4 score $\geqslant 9.28^{\text {(ref. } 17}$ ) to $12 \%$ of patients.

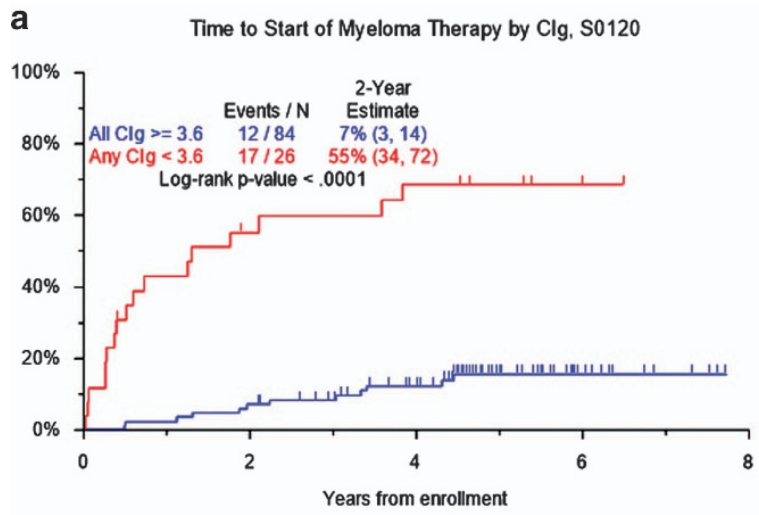

C

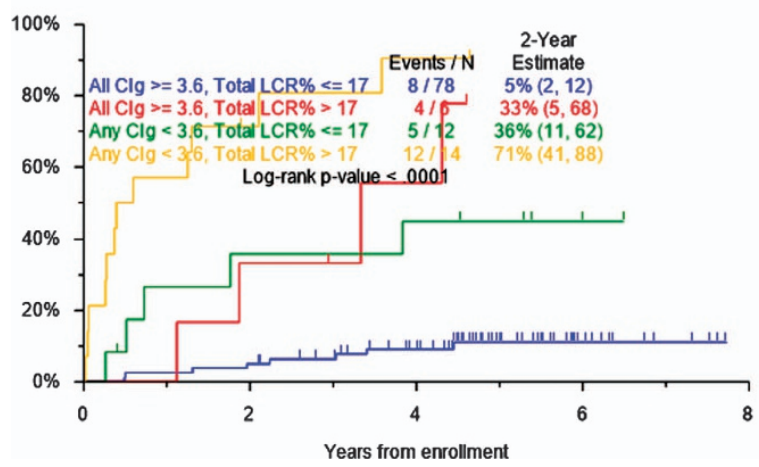

b

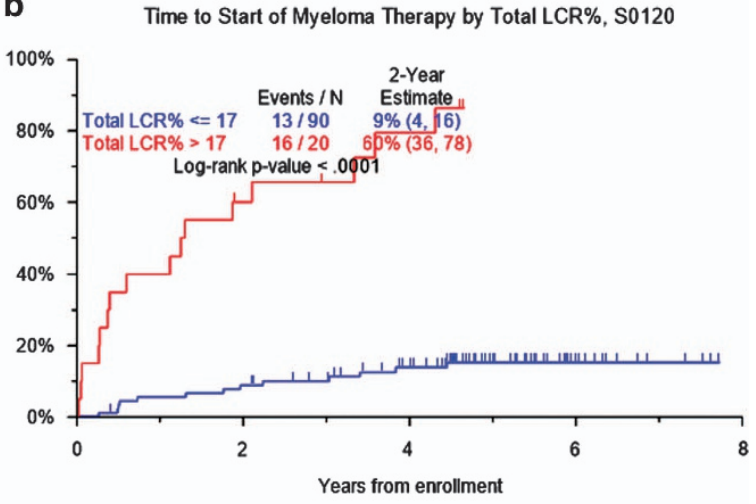

d

Time to Start of Myeloma Therapy by Number of Risk Factors, S0120 SMM Clinical risk factor: Serum M-protein $>=3$ DNACIG risk factors: Any $\mathrm{Clg}<3.6$, Total LCR\% > 17

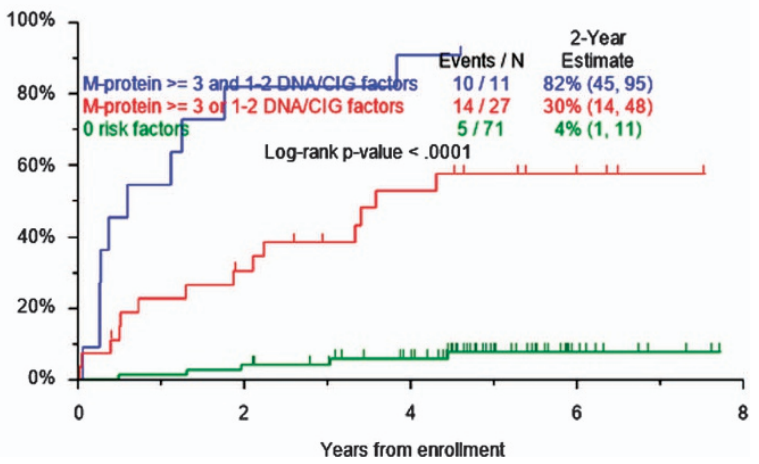

Figure 1. Kaplan-Meier plots for the time to progression from AMG to MM requiring therapy according to: Clg, (a) total LCR\%, (b) the combination of $\mathrm{Clg}$ and total LCR\% (c) and the combination of Clg and total LCR\% for the SMM population (d). 
We examined the TाT probability of AMG (Table 1). Optimal cutoff points were obtained for all continuous numerical values. We confirm other studies linking older age $\geqslant 65$ years, albumin $<3.5 \mathrm{~g} / \mathrm{dl}, \mathrm{B} 2 \mathrm{M} \geqslant 3.5 \mathrm{mg} / \mathrm{l}$, serum $-\mathrm{M} \geqslant 3 \mathrm{~g} / \mathrm{dl}$ and bone marrow plasmacytosis $\geqslant 10 \%$ (refs 3,17 ) to Tा for MM, along with an involved-to-uninvolved free light-chain ratio $>8 .{ }^{4}$ The presence of CA, GEP70- and GEP4- high-risk designations was strongly linked to inferior TाT. Among DNA/CIG-derived parameters, $\mathrm{Clg}<3.6$ and $\mathrm{LCR} \%>17$ were both strongly linked to progression to MM. Other DNA/CIG variables associated with $\Pi T$ included the presence of aneuploidy and the presence of $\geqslant 2$ DNA stem lines (Figure 1). The 26 patients with $\mathrm{Clg}<3.6$ had a 2-year $\Pi \mathrm{TT}$ probability of $55.2 \%$ compared with $7.1 \%$ among the remaining 84 with higher values (Figure 1a). Similarly, higher LCR\% >17 present in 20 patients conferred a 2-year MM progression rate of $60 \%$ versus $9 \%$ among the 90 with lower (Figure 1b). Consideration of both DNA/CIG features identified 14 patients displaying two high-risk features with 2-year $\Pi \pi$ of $71.4 \%$ as opposed to $5.1 \%$ in 78 patients with only favorable features, while the presence of one adverse variable present in 18 patients was associated with a 2-year TाT probability of approximately $34 \%$ (Figure 1c).

In the multivariate model, serum- $\mathrm{M} \geqslant 3 \mathrm{~g} / \mathrm{dl}, \mathrm{Clg}<3.6$ and LCR $>17 \%$ independently conferred adverse outcomes (Table 1 ). All three parameters combined provided for a high $R^{2}$ value of 0.861 , implying that $\Pi T$ probability could be accounted for in $86 \%$ (Supplementary Table 2). In comparison, the classical criteria of bone marrow plasmacytosis $\geqslant 10 \%$ and serum- $M \geqslant 3 \mathrm{~g} / \mathrm{dl}$ had a lower cumulative $R^{2}$ of 0.632 .

When only the sub-population of SMM (80 patients; Supplementary Table 3) was considered, DNA/CIG-derived variables retained their statistical significance (Supplementary Table 4). Both $\mathrm{LCR}>17 \%$ and $\mathrm{Clg}<3.6$ identified 14 patients with a $71 \%$ 2 -year TाT probability as opposed to $6 \%$ for the 50 patients with only favorable features; the presence of one adverse feature, present in 16 patients, was associated with a $\Pi \pi$ probability of approximately $38 \%$ (Figure 1d). The multivariate model for this cohort of patients (without GEP variables) included $\mathrm{Clg}<3.6$, $\mathrm{LCR}>17 \%$ and serum-M $\geqslant 3 \mathrm{~g} / \mathrm{dl} ; \quad$ albumin $<3.5 \mathrm{~g} / \mathrm{dl}$ and $\mathrm{B} 2 \mathrm{M} \geqslant 3.5 \mathrm{mg} / \mathrm{l}$ also conferred higher TाT probability for a $R^{2}$ of 0.862 (Supplementary Tables 4 and 5). The inclusion of GEP variables, available in a subset of 61 patients, identified GEP-4 as a significant variable, dispelling $\mathrm{Clg}$ and B2M from the model $\left(R^{2}=0.895\right.$; Supplementary Tables 4 and 6).

$\mathrm{Clg}$ is a measure of plasma cell immunoglobulin production. ${ }^{15}$ We therefore examined Clg values in patients with MGUS and SMM (both from the S0120 trial), and in newly diagnosed MM patients accrued to Total Therapy $3 \mathrm{~b} .{ }^{18}$ Median Clg values declined progressively with the transition from MGUS to SMM and later to $\mathrm{MM}(10.5$ versus 5.6 versus $3.3, P<0.001$; Supplementary Figure 1a). To exclude the possibility that the difference in $\mathrm{Clg}$ reflects the decreasing percentage of highly secreting normal plasma cells with the evolution of plasma cell dyscrasias, ${ }^{19,20}$ the analysis was repeated for strictly aneuploid cases. Again, the evolution from MGUS to SMM to MM was characterized by a progressively lower $\mathrm{Clg}$ (16.0 versus 9.1 versus 3.5, $P<0.0001$; Supplementary Figure $1 \mathrm{~b}$ ).

In summary, DNA/CIG offers powerful prognostic information for AMG even in the era of genomic profiling. While LCR\% reflects tumor burden, the finding of progressively decreasing $\mathrm{Clg}$ with the evolution of plasma cell dyscrasias in this single institution subset analysis of S0120 is novel. It provides evidence that the progression of plasma cell dyscrasias is accompanied by a progressive decline in immunoglobulin production capacity.

\section{CONFLICT OF INTEREST}

BB received research funding from Celgene Corp. and Millennium Pharmaceuticals, Inc. and is a consultant for Celgene Corp., Millennium Pharmaceuticals, Inc., Onyx
Pharmaceuticals, Inc. and Amgen, Inc. He is a co-inventor on patents and patent applications related to use of gene expression profiling in cancer medicine that have been licensed to Myeloma Health, LLC, but has no financial interests in this company. All other authors have no conflicts of interest to declare.

\section{ACKNOWLEDGEMENTS}

We thank the patients and staff of the Myeloma Institute for Research and Therapy. This work was supported in part by PO1 CA 55819 from the National Cancer Institute, and in part by the following PHS/DHHS grant numbers awarded by the National Cancer Institute, National Clinical Trials Network (NCTN): CA180888, CA180819 and CA180826.

X Papanikolaou ${ }^{1}$, A Rosenthal ${ }^{2}$, M Dhodapkar $^{3}$, J Epstein $^{1}$, R Khan $^{1}$, F van Rhee ${ }^{1}$, Y Jethava ${ }^{1}$, S Waheed ${ }^{1}$, M Zangari ${ }^{1}$, A Hoering $^{2}$, J Crowley ${ }^{2}$, D Alapat ${ }^{4}, \mathrm{~F}$ Davies ${ }^{1}, \mathrm{G}$ Morgan $^{1}$ and B Barlogie ${ }^{1}$ ${ }^{1}$ Myeloma Institute for Research and Therapy, University of Arkansas for Medical Sciences, Little Rock, AR, USA; ${ }^{2}$ Cancer Research and Biostatistics, Seattle, WA, USA;

${ }^{3}$ Yale School of Medicine, New Haven, CT, USA and ${ }^{4}$ Department of Pathology, University of Arkansas for Medical Sciences, Little Rock, AR, USA E-mail: BarlogieBart@uams.edu

\section{REFERENCES}

1 Palumbo A, Anderson K. Multiple myeloma. N Eng J Med 2011; 364: 1046-1060.

2 Landgren O, Kyle RA, Pfeiffer RM, Katzmann JA, Caporaso NE, Hayes RB et al. Monoclonal gammopathy of undetermined significance (MGUS) consistently precedes multiple myeloma: a prospective study. Blood 2009; 113: 5412-5417.

3 Dhodapkar MV, Sexton R, Waheed S, Usmani S, Papanikolaou X, Nair B et al. Clinical, genomic, and imaging predictors of myeloma progression from asymptomatic monoclonal gammopathies (SWOG S0120). Blood 2014; 123: 78-85.

4 Dispenzieri A, Kyle RA, Katzmann JA, Therneau TM, Larson D, Benson J et al. Immunoglobulin free light chain ratio is an independent risk factor for progression of smoldering (asymptomatic) multiple myeloma. Blood 2008; 111: 785-789.

5 Hillengass J, Weber MA, Kilk K, Listl K, Wagner-Gund B, Hillengass $M$ et al. Prognostic significance of whole-body MRI in patients with monoclonal gammopathy of undetermined significance. Leukemia 2014; 28: 174-178.

6 McMasters KM, Chao C, Wong SL, Martin RC 3rd, Edwards MJ. Sentinel lymph node biopsy in patients with ductal carcinoma in situ: A proposal. Cancer 2002; 95 : 15-20.

7 Edwards BK, Howe HL, Ries LA, Thun MJ, Rosenberg HM, Yancik R et al. Annual report to the nation on the status of cancer, 1973-1999, featuring implications of age and aging on U.S. cancer burden. Cancer 2002; 94: 2766-2792.

8 Bianchi G, Kyle RA, Larson DR, Witzig TE, Kumar S, Dispenzieri A et al. High levels of peripheral blood circulating plasma cells as a specific risk factor for progression of smoldering multiple myeloma. Leukemia 2013; 27: 680-685.

9 Waheed S, Mitchell A, Usmani S, Epstein J, Yaccoby S, Nair B et al. Standard and novel imaging methods for multiple myeloma: correlates with prognostic laboratory variables including gene expression profiling data. Haematologica 2013; 98: 71-78.

10 Cerny J, Fadare O, Hutchinson L, Wang SA. Clinicopathological features of extramedullary recurrence/relapse of multiple myeloma. Eur J Haematol 2008; 81: 65-69.

11 Blade J, Fernandez de Larrea C, Rosinol L, Cibeira MT, Jimenez R, Powles R. Soft-tissue plasmacytomas in multiple myeloma: incidence, mechanisms of extramedullary spread, and treatment approach. J Clin Oncol 2011; 29: 3805-3812.

12 Billadeau D, Van Ness B, Kimlinger T, Kyle RA, Therneau TM, Greipp PR et al. Clonal circulating cells are common in plasma cell proliferative disorders: a comparison of monoclonal gammopathy of undetermined significance, smoldering multiple myeloma, and active myeloma. Blood 1996; 88: 289-296.

13 Zhang Y, Roccaro AM, Rombaoa C, Flores L, Obad S, Fernandes SM et al. LNAmediated anti-miR-155 silencing in low-grade B-cell lymphomas. Blood 2012; 120: 1678-1686.

14 Barlogie B, Alexanian R, Pershouse M, Smallwood L, Smith L. Cytoplasmic immunoglobulin content in multiple myeloma. J Clin Invest 1985; 76: 765-769. 
15 Papanikolaou X, Alapat D, Rosenthal A, Stein C, Epstein J, Owens R et al. The flow cytometry-defined light chain cytoplasmic immunoglobulin index and an associated 12-gene expression signature are independent prognostic factors in multiple myeloma. Leukemia 2015; 29: 1713-1720.

16 Hiddemann W, Schumann J, Andreef M, Barlogie B, Herman CJ, Leif RC et al. Convention on nomenclature for DNA cytometry. Committee on Nomenclature. Cancer Genet Cytogenet 1984; 13: 181-183.

17 Khan R, Dhodapkar M, Rosenthal A, Heuck C, Papanikolaou X, Qu P et al. Four genes predict high risk of progression from smoldering to symptomatic multiple myeloma (SWOG S0120). Haematologica 2015; 100: 1214-1221.

18 Billadeau D, Quam L, Thomas W, Kay N, Greipp P, Kyle R et al. Detection and quantitation of malignant cells in the peripheral blood of multiple myeloma patients. Blood 1992; 80: 1818-1824.

19 Jackson DA, Elsawa SF. Factors regulating immunoglobulin production by normal and disease-associated plasma cells. Biomolecules 2015; 5: 20-40.
20 Perez-Persona E, Vidriales MB, Mateo G, Garcia-Sanz R, Mateos MV, de Coca AG et al. New criteria to identify risk of progression in monoclonal gammopathy of uncertain significance and smoldering multiple myeloma based on multiparameter flow cytometry analysis of bone marrow plasma cells. Blood 2007; 110: 2586-2592.

\section{(c) (i)}

This work is licensed under a Creative Commons Attribution 4.0 article are included in the article's Creative Commons license, unless indicated otherwise in the credit line; if the material is not included under the Creative Commons license, users will need to obtain permission from the license holder to reproduce the material. To view a copy of this license, visit http://creativecommons.org/licenses/ by/4.0/

Supplementary Information accompanies this paper on Blood Cancer Journal website (http://www.nature.com/bcj) 